\title{
Memórias e percursos semióticos do lado de Greimas
}

\author{
Jean Petitot' \\ https://orcid.org/0000-0002-9951-7944
}

I - École des Hautes Études en Sciences Sociales Paris, França

Resumo: $\mathrm{O}$ texto sumariza os longos anos de pesquisa efetuadas no contexto da semiótica estrutural de A.J. Greimas para chegar a desenvolver o modelo dinâmico introduzido por R. Thom. Ele sintetiza a contribuição desses modelos explicando como eles permitem desenvolver uma interpretação matemática coerente dos conceitos fundamentais do estruturalismo tais como Greimas os elaborou. Esse relembra igualmente as afinidades com outros desenvolvimentos teóricos da semiótica.

Palavras-chave: catástrofe; contínuo/descontínuo/discreto; estética; teoria gestáltica; iconicidade; morfodinâmica.

Abstract: Remembering Semiotic Pathways in Company with Greimas: 1970-1985 - This text summarizes the long years of work done in the context of A.J. Greimas' structural semiotics to develop the dynamical models introduced by R. Thom. It outlines the contribution of these models and explains how they can develop a coherent mathematical interpretation of fundamental concepts of structuralism as worked out by Greimas. It also recalls the affinities with other theoretical developments of semiotics.

Keywords: catastrophe; continuous/discontinuous/discrete; aesthetics; gestalttheorie; iconicity; morphodynamic.

\section{Introdução}

O centenário de nascimento de Algirdas Julien Greimas é uma oportunidade de recapitular o que lhe devo. Gostaria de precisar certos pontos.

Nosso encontro se deu em um período científico específico. Resumidamente, o contexto foi aquele da aparição dos modelos matemáticos morfodinâmicos em ciências naturais — onde o termo "morfodinâmico" qualifica os modelos dinâmicos de morfologias naturais, 
sendo os da "teoria das catástrofes" de Thom os mais conhecidos. É nesse quadro novo que reformulei o estruturalismo de Jakobson, Hjelmslev, Lévi-Strauss e Greimas. Tratava-se de unificar o estruturalismo sémio-linguístico com as matemáticas morfodinâmicas.

No final dos anos 1960, as duas margens dos meus interesses, de um lado aquela da teoria das singularidades em geometria algébrica e em geometria diferencial, de outro lado aquela dos estudos estruturais, estavam totalmente dissociados e separados pelo intransponível cânion dilthiano das Natur- / Geistes-wissenschaften. É nesse contexto que tomei conhecimento em 1968-1969 dos primeiros trabalhos que um dos meus mestres em matemática, a saber René Thom, consagrava de um lado à morfogênese biológica em ressonância com o embriologista Conrad Hal Waddington e, de outro, com o estruturalismo linguístico em ressonância com Lucien Tesnière (uma de suas referências maiores) e Roman Jakobson. Isso foi para mim uma iluminação que unificava bruscamente minhas duas ordens de interesse pois um dos melhores especialistas da teoria das singularidades acabava de construir de repente uma ponte que até então era inimaginável para o outro lado do grande cânion. Decidi então atravessar a ponte com minha bagagem matemática e engajar-me na aventura. Decidi sair do CNRS e aceitar um posto que me era oferecido no CAMS, o Centro de Matemática da EPHE Vle seção, instituição dirigida na época por Fernand Braudel que acreditava firmemente na ardente obrigação de transformar as "ciências" humanas e sociais em tecno-ciências que satisfaçam os critérios epistemológicos da modelização e da validação / falsificação empíricas.

Foi nesse novo contexto que encontrei Greimas e comecei a frequentar seu seminário. Foi um novo choque intelectual, igualmente determinante, e lembro-me do entusiasmo que me atingiu ao encontrar, no topo dos estudos estruturais, todas as qualidades que apreciava em matemáticas: o rigor inflexível, o sentido agudo da teoria, a preocupação com a formalização, a responsabilidade disciplinar, o fervor do espírito. Tudo o que alguns colegas criticaram em Greimas, ao contrário, pareceu-me ser as qualidades do verdadeiro estudioso. Encontrei também referências teóricas às minhas primeiras leituras (Lévi-Strauss, Jakobson, Hjelmslev, Tesnière) e a tese da universalidade das estruturas (neste caso, as estruturas narrativas) além da inesgotável diversidade das línguas. Valia a pena tentar compreender o que Greimas denominava "a inteligência narrativa do espírito humano" e formalizar a síntese que ele havia realizado entre a "boa" paradigmática de Lévi-Strauss e a "má" sintagmática de Propp.

Du Sens de Greimas foi publicado em 1970 e Stabilité structurelle et Morphogenèse deThom em 1972. Foi nesta efervescência que comecei a sintetizar essas duas inspirações. Vieram a seguir, do lado de Thom, os numerosos artigos cujos manuscritos eu seguia semana após semana (eles serão reunidos em grandes coletâneas como Modèles mathématiques de la morphogenèse, 1974 ; Esquisse d'une sémiophysique : Physique aristotélicienne et théorie des catastrophes, 1989 ; Apologie du logos, 1990) e, do lado de Greimas, Maupassant : La sémiotique du texte, exercices pratiques em 1976, Introduction à la 
sémiotique narrative et discursive de Joseph Courtés igualmente em 1976, e Sémiotique. Dictionnaire raisonné de la théorie du langage de Greimas e Courtés em 1979, três obras lidas e relidas que me permitiram consolidar esta síntese.

Assim como Greimas trabalhou constantemente de dois "lados", do lado de Propp e do lado de Lévi-Strauss, também trabalhei de dois "lados" tentando enriquecer a semiótica estrutural greimassiana por meio das matemáticas thomianas e a modelização lingüística thomiana pelo modelo actancial greimasiano. E parafraseando o narrador de La Recherche, sempre penso no "lado de Greimas" e no "lado de Thom" como "camadas profundas do meu solo mental".

\section{O contexto disciplinar e institucional}

No curso dos anos 1970-1985, minhas pesquisas estiveram em grande parte voltadas para os fundamentos teóricos e os modelos do estruturalismo, e isso em dois domínios: a fonologia e as estruturas semionarrativas. Elas foram realizadas em um ambiente rico e diversificado. Em primeiro lugar, obviamente, no círculo greimassiano e suas redes internacionais. A história é agora bem conhecida. Como todos meus colegas semioticistas, guardo uma lembrança incomparável dos seminários magistrais de Greimas, em particular na Faculdade de Teologia Protestante do 83, boulevard Arago, em Paris. O grande colóquio de Cerisy, Sémiotique en jeu, organizado por Michel Arrivé e Jean-Claude Coquet de 4 ao 14 de agosto de 1983 (publicado em 1987) permanece um momento-chave e uma memória indelével.

Muito cedo, Paolo Fabbri me colocou em contato com o grupo de Umberto Eco em Bologna e Umberto ajudou-me enormemente. Seu convite para eu ir ao DAMS como professor associado em 1981 teve um papel muito importante na redação definitiva de minha tese (defendida em 1982). O Centro Internazionale di Semiotica e di Linguistica da Universidade de Urbino criado em 1970 por Fabbri e Pino Paioni graças ao reitor Carlo Bò (Centro do qual Greimas foi o primeiro diretor) e mais tarde o International Center for Semiotic and Cognitive Studies da Universidade de San Marino (com Patrizia Violi) foram lugares mágicos de interdisciplina.

É também no Center for Semiotics, criado em 1993 na Universidade de Aarhus por Per Aage Brandt, que o estruturalismo morfodinâmico, e, mais tarde, a sua junção com a linguística cognitiva californiana (cf. mais abaixo), vão ser desenvolvidos; nosso colega alemão Wolfgang Wildgen, especialista de linguística thomiana, aí contribuiu também amplamente (cf. sua obra de 1982, Catastrophe Theoretic Semantics).

Teve também as ligações com a semiótica norteamericana, Thomas Sebeok e as Escolas de Verão de Toronto, bem como com a IASS (International Association for Semiotic Studies). Guardo uma boa lembrança do terceiro Congresso quinquenal organizado em junho de 1984 em Palermo por Antonio Buttita (o primeiro Congresso, decidido em 
1969, teve lugar em Milão em junho de 1974 e o segundo em Viena em junho de 1979). Tendo-me tornado vice-presidente pela França, pude participar das reuniões do Comitê. Quando da realização em Palermo em abril de 1986, encontrei, entre outros, o presidente Jerzy Pelc (que será presidente até 1994), Greimas, Antonino Buttita, Thomas Sebeok, Paul Bouissac, Roland Posner (qui sucedera a Pelc em 1994 depois do Congresso de Berkeley), Gérard Deledalle, Jeff Bernard, Gloria Withalm e Martin Krampen. Certo, as diferenças eram patentes entre as duas semióticas, peirceana e estrutural, bem como entre uma semiótica concebida como uma abordagem do sentido autônoma, geral, teoricamente coerente e metodologicamente rigorosa (aí reconhece-se a posição de Greimas) e uma semiótica interdisciplinar que considerava toda e qualquer tentativa de fundamentação, em particular estrutural, como um fracasso e visava simplesmente estudar os aspectos semióticos de outras ciências (a linguística, as ciências cognitivas, a neurobiologia, a psicologia da percepção, a inteligência artificial, a comunicação, as medias, etc.). No entanto, apesar dessas diferenças, a atmosfera era excelente.

A partir de 1986, ingressei no grupo de ciência cognitiva criado por Daniel Andler no CREA fundado em 1982 na Escola Politécnica por Jean-Pierre Dupuy e, em 1989, comecei a participar do DEA de Ciências Cognitivas (EHESS, Paris VI, Polytechnique) criado pelo especialista das neurociências da visão Michel Imbert (ao qual sucedi como responsável do DEA em 2000). Mas, apesar dessa inflexão de minha pesquisa, permaneci intimamente conectado com o meio semiótico.

Após a partida de Greimas para a aposentadoria em 1984, haviam somente Christian Metz e eu que, como diretores de estudos na EHESS, realmente tinham trabalhado com ele. A Escola me pediu para garantir uma certa continuidade administrativa do 10 rue Monsieur-le-Prince ${ }^{1}$. Aceitei essa responsabilidade no quadro de minha direção de estudos em Épistémologie des modèles, mas isso não podia ser suficiente nem para garantir a continuidade do GRSL (Groupe de recherche sémio-linguistique), do qual Metz e depois Courtés tinham sido responsáveis, nem para preservar o estatuto prévio das publicações do Grupo, as Actes Sémiotiques (com, no início, Anne Hénault e, até hoje, Eric Landowski). E depois do passamento de Greimas em 1992 e do de Metz em 1993 havia somente meu seminário e minha pequena equipe de Épistémologie des modèles sémiotiques et cognitifs (EEMSC) para representar a semiótica na École, o que era de fato insuficiente. Várias vezes tentei convencer as instâncias superiores da EHESS da necessidade de abrir uma direção de estudos de semiótica, mas isso sempre falhou.

De qualquer forma, tentei preservar um ensinamento de semiótica. Em primeiro lugar, graças ao meu próprio seminário, e depois a partir de 1990, graças a um seminário com Jean-Claude Coquet, que possibilitou dialetizar a modelização da semiótica "objetal" com a epistemologia da semiótica "subjetal", enfim, a partir de 1997 (e até em 2012) graças a um seminário com Ivan Darrault, Jean-Jacques Vincensini e Michel Costantini em que foram

1 Endereço do Grupo de pesquisa semio-linguística (GRSL) de Greimas em Paris. (NdT) 
longamente abordados, entre outros temas, a psico- e a etno-semiótica, a fenomenologia do corpo próprio e do "embodiment" do sentido, a antropologia (mitos e ritos), as narrações medievais, os estudos estéticos e o estruturalismo nas artes plásticas (pintura e escultura: o Laocoon de Goethe, Lévi-Strauss sobre Poussin, etc.), a genealogia morfológica desde o estruturalismo de Goethe até o formalismo russo e Jakobson. Igualmente propus, a partir de 1994, a inscrição do Séminaire intersémiotique de Paris entre os ensinamentos da EHESS.

Mas isso não podia bastar para assegurar a perenidade institucional da semiótica. Felizmente, Jacques Fontanille dirigiu energicamente as coisas na Université de Limoges e Eric Landowski tomou conta das publicações. Com a posição universitária de JeanClaude Coquet na Paris VIII e aquela de Anne Hénault na Sorbonne, assim como, depois, progressivamente aquelas de vários outros colegas, a semiótica pode corajosamente defender sua posição.

\section{Afinidades e alianças da morfodinâmica}

Os modelos dinâmicos de estruturas elementares elaborados nos anos 1970 se situavam em um duplo contexto, aquele do progresso endógeno da semiótica "objetal" greimasiana e aquele da morfodinâmica thomiana. Ora essa última mantinha com as outras disciplinas numerosas afinidades e alianças que muito naturalmente tentei transferir para a semiótica. Daí um certo número de aportes "exógenos" à teoria standard que frequentemente se compreendeu e aceitou mal ${ }^{2}$. Sabe-se que para Greimas a coerência da teoria era essencial e que ele não aceitava as importações conceituais que não fossem reconceptualizadas semioticamente. De um lado, ele queria autonomizar a semiótica em relação a outras ciências sérias e, de um outro lado, ele rechaçava os contágios filosóficos porque para ele as atitudes filosóficas eram fatalmente dóxicas e não epistêmicas e, por falta de operatividade, condenavam o pensamento ao eterno conflito de opiniões. Felizmente certos progressos endógenos da semiótica mais tarde convergiram em direção a esses aportes exógenos, o que, além disso, é muito interessante do ponto de vista da história das ideias.

\section{Physis e technè: matemática do hilemorfismo}

Uma das principais contribuições de estudiosos como Alan Turing (equação de reaçãodifusão), René Thom (catástrofes e bifurcações), Ilya Prigogine (estruturas dissipativas), Hermann Haken (sinergética), Henri Atlan (ordem a partir do barulho) nos anos 19501970 (para apenas citar alguns deles) constituiu em mostrar que o mundo microscópico físico-químico envolvendo miríades de interações complexas entre unidades elementares

2 Quis honrar a teoria de Greimasiana usando o termo habitual na época para indicar a teoria de referência de partículas elementares que unificava as grandes forças de interação, ou seja, o "modelo standard" elaborado nos anos 1960 por Glashow, Weinberg et Salam (eles obtiveram por tal o Nobel em 1979). Por essa razão, falei de " teoria standard ». Mas (eis um bom exemplo das diferenças de cultura entre disciplinas) isso foi interpretado negativamente por numerosos semioticistas (e talvez por Greimas ele mesmo), embora "standard", pelo contrário, qualifique a referência a partir da qual os modelos podem desenvolver suas sínteses computacionais. 
possuía em si mesmo propriedades auto-organizacionais permitindo que morfologias macroscópicas emergissem dos substratos materiais. Os exemplos são inumeráveis na natureza: as grandezas termodinâmicas (como a temperatura, a pressão ou o volume) interpretáveis em termos de física estática, a forma das gotas de água ou das ondas, os turbilhões e outros redemoinhos e turbulências, as formas das dunas de areia que emergem de miríades de avalanches fractais microscópicas, todos os desenhos que se observa sobre as conchas ou as pelagens e que emergem de interações celulares, todos os processos psicológicos que emergem da agregação coerente de miríades de potenciais de ação neuronais, etc., etc. Em uma palavra, o mundo material natural tem recursos imanentes para se estruturar em formas. Para retomar um belo neologismo de Per Aage Brandt, pode-se falar de uma "fenofísica" macroscópica emergente.

É essencial compreender que o nível morfológico "feno-físico" é objetivo. Com efeito, desde a época moderna (mas poder-se-ia remontar ao atomismo grego), as ciências são prisioneiras de uma aporia. Elas postulam que há uma física fundamental "micro" dos componentes elementares da matéria e das suas forças de interação. Mas não tendo nenhuma possibilidade de desenvolver uma dinâmica matemática das formas macro emergentes, elas postulam que essas são engendradas pela percepção e, portanto, de essência subjetiva. Depois, em um segundo tempo, por falta de saber como modelizar o sensível de outro modo que o descrevendo por meio da linguagem, elas identificam a percepção aos julgamentos perceptivos e, portanto, o mundo "feno-físico" se torna um negócio de enunciados linguísticos e de conteúdos mentais. Assim foi criado um abismo entre a objetividade física e o mundo natural. Como dizia Greimas (Conclusão do Colóquio de Cerisy, 14 de agosto de 1983), o mundo se constitui a partir da linguagem.

Surgidos nos anos 1950-1970, não somente os novos modelos à la Turing-ThomPrigogine tinham um enorme alcance científico, mas também eles preenchiam essa lacuna e resolviam em parte o problema metafísico subjacente, aquele do hilemorfismo, que atravessou os séculos de Aristóteles a Leibniz e de Leibniz ao estruturalismo (o estruturalismo é uma versão moderna do hilemorfismo).

Na Critique de la Faculté de Juger onde ele trata da organização do mundo natural em formas, isto é no fundo do hilemorfismo, Kant fala de technè da Natureza e opõe a capacidade que tem a Natureza de produzir formas à física mecânica de seu tempo. A natureza não é apenas "physis", ela é igualmente "poièsis" (Kant fala de uma Natureza como "Arte"). E é mesmo a oposição metafísica tradicional entre physis e technè que se encontra completamente renovada pela "feno-física" hilemorfista.

A antinomia dialética physis / logos, muito bem analisada por Jean-Claude Coquet na sua obra epônima consagrada à fenomenologia da linguagem (voltarei a isso depois), pode, portanto, se desenvolver (o que tentei fazer) em um ternário physis / technè / logos (que não é um tipo de Aufhebung hegeliana). Em relação à techné, a physis refere-se à implementação física, química, bioquímica, das formas, ao passo que, em relação a essa mesma technè, o logos diz respeito à conversão das morfologias em estruturas formais. 
O ponto de Arquimedes é de compreender que a Natureza como techné é uma Natureza que possui nela mesma os recursos de sua fenomenalização, uma Natureza cujas forças e energias internas se desdobram em formas externas.

\section{Mereologia e Morfologia goethiana}

É nesse contexto que a modelização das estruturas elementares saídas da esquematização dos indefiníveis semióticos rápida e naturalmente criaram interfaces com outras tradições de pensamento.

Primeiro a mereologia. De fato, a noção de estrutura é um aspecto particular do problema mereológico tradicional das relações entre todo e partes ou, mais precisamente, das relações internas entre partes em um todo autoorganizado e autoregulado. Sob o nome de "finalidade interna objetiva", essa questão metafísica da organização encontra-se no coração não só da Critique de la Faculté de Juger de Kant, mas também da Morphologie de Goethe que decorre diretamente dela. Além disso, a terceira Crítica kantiana unifica a "finalidade interna objetiva", do lado biológico, com a "finalidade subjetiva formal", do lado estético. Ainda em filiação direta, Goethe também desenvolveu um monismo morfológico válido tanto para os organismos biológicos (veja sua Métamorphose des plantes) quanto para as obras de arte, que ele tratava como organismos (cf. seu Laocoon). A esse título, ele é o precursor do estruturalismo.

A partir dos anos 1990, trabalhei muito sobre o fato, na minha opinião central para a história das ideias, que a morfodinâmica thomiana e o estruturalismo lévi-straussiano se valiam ambos da morfologia de Goethe que tentei reconstruir no que denominei "a genealogia morfológica do estruturalismo". Foi bastante fascinante. A doutrina goethiana foi retomada pelo formalismo russo dos anos 1920: Petrovskij (1921: análises de Voyage de Maupassant e de Pouchkine), Vasily Gippius (1919: Urmorphologie, papéis e funções nas novelas de Tourgueniev), Alexander Nikiforov (papéis e funções em contos populares), Alexander Reformatskij. Para não mencionar Victor Chklovski (fundador do grupo de São Petersburgo), um aluno de Baudoin de Courtenay que iniciou o estruturalismo em fonologia com a noção de fonema e encontra-se na origem das escolas de São Petersburgo, Moscou e Praga. E é necessário recordar que o título e as epígrafes de $A$ morfologia do conto de Vladimir Propp vêm de Goethe. Sobre tudo isso, o leitor interessado poderá se referir entre outras às obras de Tzvetan Todorov, Jean-Marie Schaeffer, Yuri Lotman, Lubomir Doležel, Sergei Tchougounikoff, Patrick Sériot, Michel Aucouturier, Sylvie Archaimbault e Michel Espagne.

A mereologia é ainda particularmente bem explicitada por Husserl na sua Troisième Recherche Logique que foi essencial para Jakobson (como bem foi mostrado por Elmar Holenstein), assim como para Hjelmslev. 


\section{Teoria Gestaltáltica e fenomenologia da percepção}

Outro aspecto essencial da morfodinâmica é de permitir compreender porque e como a organização morfológica do mundo natural domina a percepção, a percepção visual claro, mas também todas as outras percepções. Ela mantém uma conexão estreita com a Teoria da Gestalt (Stumpf, Meinong, von Ehrenfels, Köhler, Koffka, Wertheimer, Kanizsa, etc.) e a fenomenologia da percepção (Husserl, Merleau-Ponty). Mesmo antes de fazer a ligação com o estruturalismo greimasiano, tinha desde o início entrevisto esse vínculo essencial entre a auto-organização morfológica do mundo natural, como Thom a modelizava, e a fenomenologia husserliana da percepção (especialmente na Troisième Recherche Logique e o primeiro volume de Ideen zu einer reinen Phänomenologie traduzido em 1950 por Paul Ricœur). No nível epistemológico, essa descoberta foi de grande importância porque mostrava que, ao contrário do antinaturalismo husserliano, a percepção se articulava ao mundo das formas naturais: era a ausência completa na sua época de uma matemática hilemorfista que tinha obrigado Husserl a desenvolver uma alternativa subjetivista idealista radicalmente antinaturalista.

\section{Iconicidade dos papéis casuais}

Na medida em que se encontram justificadas abordagens morfodinâmicas conjuntas (i) do estruturalismo em geral como uma ciência mereológica, (ii) da organização morfológica do mundo natural, (iii) da fenomenologia da percepção e da teoria da Gestalt, (iv) das sintaxes actanciais, é normal perguntar-se neste contexto sobre as raízes perceptivas da gramática. Já desde Topologie et Signification (1968) e Topologie et Linguistique (1970), Thom havia ligado os gráficos actanciais à la Tesniere, que ele tinha conseguido derivar das catástrofes elementares, com a percepção das interações espaçotemporais entre actantes espaciais. Esta tese fundamental sobre a origem da linguagem afirma uma iconicidade profunda da sintaxe e, mais precisamente, das sintaxes casuais, porque os papéis actanciais são papéis casuais. Liguei muito rapidamente isso a duas coisas: (a) a obra-prima de Hjelmslev La catégorie des cas (1935) e ao que foi chamado, desde os gramáticos bizantinos (Maxime Planude, Théodore Gaza, retomando o trabalho do alexandrino Apollonius Dyscole), a hipótese localista, (b) as gramáticas casuais da linguística da época, particularmente as de Charles Fillmore em Berkeley (1968) e John Anderson em Edinburgh (1971).

Esta geometria icônica da gramática (totalmente diferente da combinatória das gramáticas gerativas), construída sobre matemáticas específicas sofisticadas, se desenvolveu consideravelmente a partir dos anos 1980, na França em grande parte graças aos ricos trabalhos de Bernard Pottier em semântica geral (1992, 2000) e, no estrangeiro, graças aos contatos estabelecidos por Per Aage Brandt com a linguística cognitiva californiana de 
Len Talmy (Berkeley e Buffalo), Ron Langacker (San Diego), George Lakoff (Berkeley, em colaboração com Mark Turner e Mark Johnson), Gilles Fauconnier (San Diego, também em colaboração com Mark Turner). Esta "iconicidade na sintaxe" (cf. John Haiman, 1985), na qual o papel das "imagem-esquemas" é central, reencontrou de modo independente uma parte do esquema catastrofista, mas de modo simplesmente figurativo, sem qualquer justificação matemática. Por outro lado, ela imergiu a linguagem nas neurociências cognitivas da percepção e da ação e modificou profundamente a concepção que se pode fazer da linguística. Meus vinte e cinco anos de trabalho nesse campo foram sintetizados em Cognitive Morphodynamics. Dynamical Morphological Models of Constituency in Perception and Syntax publicados em 2011 por Peter Lang na coleção chamada European Semiotics dirigida por Per Aage Brandt e Wolfgang Wildgen.

\section{A anfibologia dos conceitos estruturalistas}

Está por trás de tudo isso um problema filosófico maior cuja história é antiga. Em suas afinidades lógicas, a semiótica formalista permanece solidária a uma vasta gama de concepções que privilegiam as análises conceituais, as gramáticas lógicas, as regras do pensamento (as "ideias", o "inteligível", como se dizia no século XVII e XVIII na época dos «ensaios» e outras "pesquisas" sobre o "entendimento" humano) em detrimento das sínteses perceptivas, das Gestalten intuitivas e das morfologias espaço-temporais. Ao se concentrar nas formas lógicas, utiliza-se o plano do conteúdo (o "inteligível") para fazer comunicar entre eles planos de expressão heterogêneos. Poder-se-ia voltar até o famoso ut pictura poesis de Horace, que atravessou os séculos.

Assume-se que existem conteúdos abstratos de formato proposicional sobre os quais operam as atitudes proposicionais. "Ver" $p$, "desenhar" $p$, "ouvir" $p$, "dizer" $p$, "pensar" $p$, etc. comunicam então entre eles via o conteúdo proposicional invariante $p$ e tornam-se intertraduzíveis. Em termos mais cognitivos, a hipótese é que os conteúdos são mentais (sempre as "ideias"), que o espírito é multimodal e que as diferentes modalidades (percepção, ação, etc.) podem se comunicar entre elas por meio das representações amodais abstratas que são as proposições. Entretanto, não há nenhum motivo para que as estruturas conceituais que fazem comunicar entre eles os diferentes tipos de informação sejam de formato proposicional. Muito ao contrário. Existem formatações diferentes e é a mudança de formato que se trata de entender.

Aliás, a concepção "proposicional" não é compatível com os dados experimentais das neurociências cognitivas que mostram que as diferentes modalidades têm formatos específicos associados às arquiteturas funcionais das áreas corticais correspondentes. Ela é, ademais, semioticamente insuficiente. Nela, o jogo hjelmsleviano quadripartido conteúdo / expressão e forma / substância se reduz a um simples binarismo entre um conteúdo amodal e diferentes modos de manifestação, isto é, a um plano do conteúdo mental e 
proposicional universal, sem plano de expressão específico, e a planos de expressão sem planos de conteúdo específicos.

Bem entendido, a semiótica escapa, por definição, a essa limitação. Mas ela não escapa à análoga semiótica do que se encontra nas "imagens lógicas" do jovem Wittgenstein ou na "construção lógica do mundo" de Carnap, a saber, a hipótese de uma forma lógica imanente ao real, de um real que seria dado diretamente em uma forma lógica, linguística ou semiótica. Ao fazer da semiótica do mundo natural e, portanto, da fenofísica e da percepção, uma semiótica, ela supõe que uma forma semiótica está aí originalmente ativa.

A primeira crítica filosófica maior das posições desse gênero foi desenvolvida por Kant sob o nome de Amphibologie. Na filosofia crítica, o termo anfibologia refere-se às ambiguidades decorrentes (i) da incapacidade de desemaranhar o que pertence a uma análise categorial e o que diz respeito a uma estética transcendental, e (ii) da obstrução de toda esquematização que daí resulta. Esse problema foi consideravelmente aprofundado por Husserl em Erfahrung und Urteil (1939), onde ele analisa os fundamentos perceptivos ante-predicativos e pré-judicativos subjacentes às "formas categoriais" predicativas dos julgamentos e de sua "analítica" lógica. René Thom foi ainda mais longe ao analisar o que ele chamava de "o hiato entre a lógica e a morfologia". Não é aqui o lugar de aprofundamento sobre este ponto, mas digamos que, nas abordagens formalistas não esquematizadas da semiótica, os conceitos estruturalistas são necessariamente fortemente anfibológicos devido à falta de estética transcendental e que o recurso a sínteses computacionais derivadas de esquematizações-construções-modelizações é a única maneira de superar esse obstáculo epistemológico.

\section{A unificação das ciências estruturais}

\section{Matemáticas transdisciplinares}

Existe uma certa universalidade na diversidade das estruturas morfológicas e dos fenômenos críticos que Ihe são constitutivos. Por conseguinte, justifica-se, muito além das vagas analogias, visar uma teoria unificada das morfologias naturais: das morfologias macrofísicas à morfogênese biológica e das Gestalten perceptivas às estruturas actanciais. A feno-física hilemorfista se desenvolve por si mesma em morfogênese e em semiofísica (cf. meu livro Physique du sens, 1992).

Todas as afinidades e alianças ricas e variadas que acabamos de mencionar e que conduzem à unificação das ciências estruturais transformam profundamente o estatuto da semiótica standard e, digamos para ser breve, a inscrevem em um horizonte de naturalização do sentido, mas de uma naturalização "emergencial" radicalmente não-reducionista resultante, como já vimos, do alargamento da physis da Natureza 
a uma technè da Natureza. No plano da história das ideias, isso é bastante interessante. A esquematização-modelização das estruturas elementares em termos de desenvolvimentos universais de singularidades pode, sem dúvida, ser restrita a uma pura matematização. Mas, na medida em que os mesmos modelos têm inúmeras aplicações em muitos outros domínios, ela conduz naturalmente a fazer aparecer solidariedades inesperadas e, de repente, a repensar profundamente as fronteiras disciplinares.

Esse ponto é crucial na filosofia da ciência: os modelos matemáticos unificam os domínios heterogêneos porque eles mostram comunidades, e, às vezes, isomorfismos, de estrutura. O primeiro exemplo espetacular foi a unificação pela gravitação universal newtoniana das trajetórias planetárias do mundo "supralunar" e das trajetórias balísticas do mundo "sublunar" (todas as tecnologias de satélites são baseadas nessa unificação). Um outro belo exemplo é a comunidade de estrutura entre os vidros de spins na teoria do magnetismo e nas redes neuronais. Essas solidariedades provêm evidentemente do fato de que as matemáticas são ontologicamente neutras, funcionam apenas no isomorfismo e não tem vínculo privilegiado com nenhum domínio substancial particular da realidade. Um exemplo particularmente óbvio é aquele das simetrias, que são universais: encontrase em muitos domínios (cristais, vírus, radiolários, etc.) tetraedros, hexaedros, octaedros (correlatos dos hexaedros), dodecaedros e icosaedros (correlatos dos dodecaedros) porque esses poliedros regulares convexos (sólidos platônicos do Timeo) correspondem aos três subgrupos finitos fundamentais do grupo de rotações do espaço. O mesmo vale exatamente para os modelos morfodinâmicos, que são além disso em uma certa medida modelos universais de ruptura de simetria.

Tais transformações da "geografia política" dos saberes apenas podem ser vividas no início como "exógenas" pelas disciplinas em questão (pensemos ainda na virada do século XVII nos matemáticos astrônomos que se uniram aos engenheiros de artilharia, ou, mais perto de nós, nos biólogos naturalistas que se encontraram com os físicos especialistas em difração sob raios X para inventar a biologia molecular, ou ainda aos lógicos puros que se reencontraram com engenheiros eletrônicos para inventar a informática). No entanto, ela é apenas uma consequência do fato de que os modelos bem construídos geralmente dão origem a analogias unificadoras entre domínios empíricos completamente diferentes.

O mesmo se aplica à semiótica estrutural. Suas afinidades e alianças disciplinares tradicionais estavam do lado da linguística, da lógica, da crítica literária, da estética, da antropologia e, obviamente não, salvo exceção (cf. o naturalismo de Lévi-Strauss ou a última filosofia da natureza de Merleau-Ponty) do lado da biologia naturalista, da teoria da Gestalt, da topologia ou das equações diferenciais. Ora, são precisamente novas afinidades e alianças deste tipo que a abordagem morfodinâmica promoveu. 


\section{A semiótica do mundo natural}

Dado tudo o que foi explicitado anteriormente a propósito da morfodinâmica como uma matemática hilemorfista não da physis, mas da technè da Natureza, compreender-se-á facilmente que já não era mais possível considerar o que se chamava a semiótica do mundo natural como uma simples semiótica figurativa de superfície capaz de produzir efeitos de "ilusão referencial". Muito antes, essa semiótica dizia respeito ao fato de que a semiose era constrangida pela organização morfológica do mundo natural. O figurativo não se confinava mais no nível discursivo superficial, mas, enquanto componente de uma iconicidade profunda, estendia-se a uma estética transcendental da articulação do sentido.

Nos anos de 1975 a 1985, o que parecia pertencer a um "realismo perceptivo" foi discutido no seminário de Greimas, mas geralmente foi rejeitado em nome da ilimitação da semiose. Lembro-me, em particular, de sessões divertidas do seminário 1984-1985, onde discutimos para saber se o modo pelo qual um escritor descrevia uma epifania estética era ou não constrito pela percepção da figura. Defendi a tese de que este era realmente o caso, e isso muito além da diferença clássica introduzida por Greimas a partir de Semântica estrutural entre os semas nucleares exteroceptivos que descrevem as figuras do mundo e os classemas interoceptivos que descrevem os efeitos do sentido. Pois uma epifania estética é sempre uma infinitização do percebido como tal e não uma semiotização classemática. Trata-se do "sublime" que induz à transformação do estado passional do sujeito tão característico da apreensão estética. O que Mallarmé chamou, em Prose pour des Esseintes (poema que havia analisado em um estudo publicado mais tarde, em 1989, sob o título de "La lacune du contour"), o "lúcido contorno", isto é a perfeição da linha e da pura morfologia infinitiza o percebido e faz dele um Destinador, se se pode dizer, "a flor de forma". Winckelmann já explicou isso: a perfeição das linhas e dos contornos comporta nela mesma uma expressão "divina" da "alma". Encontra-se a mesma coisa em Kant, Goethe, Proust, Valéry e tantos outros.

Ora, para Greimas, a filosofia da estética se situava "fora da semiótica" e para ele não se podia homologar elementos de uma forma de expressão figurativa com os significados profundos de uma semântica fundamental. O debate que me interessava não aconteceu, portanto, na Paris da época.

Mas aconteceu muito mais tarde e em outro contexto, em Bolonha com Umberto Eco. O contexto era aquele do modo como a linguagem pode falar do visível, com todas as tradições retóricas relacionadas, as da hipótipose, da ekphrasis, ou da enargeia desde a Antiguidade (Hermogene, Longin, Cicero, Quintiliano). Herman Parret falou magnificamente sobre essas tradições em 1996 no Colóquio de Cerisy Au nom du sens que organizei em homenagem a Umberto com Paolo Fabbri.

Em Kant e o Ornitorinco (1997), Eco afirmou a existência de formas pré-semióticas de realidade, de "qualquer coisa no contínuo da experiência que impõe limites às nossas interpretações". O ponto teórico fundamental era que o contínuo hilético do sentido não 
é amorfo e que, ao contrário, ele é mesmo morfogene, que é um princípio de formação. É pré-estruturado e, como tal, condiciona a possibilidade de uma semiotização. Um pouco antes (1996), em seu texto // referimento rivisitato (aliás reimpresso em Kant e o Ornitorinco), Eco falava sobre as "linhas de resistência do ser" usando uma bela analogia: "Na massa do contínuo existem linhas de resistência e possibilidades de fluxo, como as nervuras da madeira ou do mármore, que facilitam o corte em uma direção mais do que em outra?" E ele precisava: "O ser não é o que é no sentido em que ele seria livremente construído pela linguagem. (...) A linguagem não constrói o ser ex novo". Isso em comparação com a afirmação de Greimas, evocada acima, que o mundo se constituí a partir da linguagem.

Mas Eco tomou grande cuidado de não reduzir esta tese a algum "vétero-realismo" que teria postulado, como fazia a filosofia medieval, uma adaequatio rei e intellectus. Como ele explicou em uma nota de 2012 na revista Alfabeta, ele queria criticar "o primado hermenêutico da interpretação" e a tese nietzschiana segundo a qual "não existem fatos mas apenas interpretações". Seu realismo a propósito do que ele chamava de "base dura do ser" era um realismo negativo que se limitava a impor constrições.

No fundo, é talvez em termos peirceanos que se poderia melhor formular tudo isso dizendo que o nível morfológico "feno-físico" do mundo natural depende de uma primeiridade morfológica. Ele pertence, juntamente com os qualia, a esse iconismo primário que Eco considerava como o "limiar inferior da semiótica" estabelecendo o vínculo da semiose com a percepção. O ponto é que o iconismo primário é nele mesmo um princípio diferencial e morfogênico no qual se fundam as diferenças semioticamente pertinentes. Dito de outro modo, a primeiridade da fenomenalidade compreende as discontinuidades qualitativas (em particular espaço-temporais) e a terceiridade semiótica semiotiza diferenças primariamente perceptivas.

Este debate é detalhado em minha homenagem de 2016, "Semiotic enargeia: a tribute to Umberto Eco".

\section{Semiótica e fenomenologia}

Tendo assim correlacionado a "feno-física" e a fenomenologia da percepção, com as consequências que acabamos de ver para a semiótica do mundo natural, tornava-se normal tentar coordenar diretamente fenomenologia e semiótica. Conforme mencionado acima, as ligações já estavam bem documentadas para o estruturalismo de Jakobson e Hjelmslev. No início (nos anos 1970), não conhecia as ligações entre Merleau-Ponty e Greimas que permaneceu bastante discreto sobre isso. Mas a situação mudou durante a década de 1980. Primeiro, graças às extraordinárias trocas entre Greimas e Ricœur, por exemplo durante o Colóquio de Cerisy Sémiotique en jeu (debate do 11 de agosto de 1983). Em seguida, graças a alguns semioticistas fenomenólogos como Jean-Claude Coquet ou Hans-George Ruprecht. E após o passamento de Greimas, vários depoimentos sublinharam essas afinidades. Voltarei a isso. 


\section{Afetos tímicos e objetos-valores}

No que precedeu, várias vezes indicamos a ligação existente, em Kant e Goethe, entre a organização morfológica do mundo natural (a techné da Natureza) e o sentimento estético. Essa problemática correlaciona a percepção das formas ao "sentimento", isto é, a afetos tímicos. Esta correlação está igualmente presente em Husserl, e de forma particularmente bem sucedida. Discuti isso em 1985 no artigo "Jugement esthétique et sémiotique du monde naturel chez Kant et Husserl", publicado nas Actes Sémiotiques.

No Volume II de Ideen (que está na origem de várias obras de Merleau-Ponty), Husserl estabeleceu um paralelo entre a fenomenologia da percepção e a fenomenologia dos objetos-valores. Na primeira, a hyle é a hyle sensorial e as sínteses noéticas produzem como correlatos noemáticos os objetos percebidos em movimento num mundo tridimensional. Na segunda, a hyle é o afeto e as sínteses noéticas produzem, como correlatos noemáticos, objetos investidos de valores (sejam esses estéticos, tímicos ou éticos). Husserl formula as coisas assim: "O valor é o correlato noemático do afeto". O objeto-valor é uma "forma avaliada" objeto de um "desejo avaliativo" e esta camada semiótica se funde sobre a camada morfológica dada pela percepção: o valor se funde na forma percebida.

Mas na medida em que os afetos pertencem ao corpo, uma fenomenologia dos objetos-valores faz intervir o corpo próprio vivo (a "carne" em Merleau-Ponty). Há, como diz Husserl, momentos dinâmicos e energéticos, de tensão, de relaxamento, de inibição, de descontração do corpo proprioceptivo que constituem os fundamentos hyléticos da vida de desejo e vontade. Vê-se a proximidade com a concepção de Greimas dos sujeitos intencionais modalizados e dos objetos-valores e, ainda mais, com a tensividade do vivido no sentido de Zilberberg, tensividade que nós já mencionamos. A vantagem da fenomenologia é a correlação explícita e tematizada com o Leibkörper e tudo o que mais tarde se tornará a problemática da "corporeidade" — do "embodiment" — do sentido.

\section{Ciências sociais e estruturalismo noético}

A modelização morfodinâmica das estruturas elementares formais se inscreve assim numa dupla perspectiva substancial, por um lado aquela, "hylemorfista", de uma "feno-física" da techné da Natureza, por outro lado aquela do psiquismo e do corpo próprio, que esses sejam concebidos no sentido das neurociências cognitivas, do embodiment da linguagem e do sentido ou da fenomenologia do Leibkörper. Isso não é absolutamente incompatível com o fato de que, como Greimas aí sempre insistiu, a semiótica se baseia nas grandes ciências antropológicas e sociais, de Durkheim a Mauss, Dumézil e Lévi-Strauss e, como o diz Courtés, "se situa na confluência da antropologia e da linguística".

É importante notar isso, porque o estruturalismo dos anos 1960 se desenvolveu num contexto ideológico em que o social e seu controle político se afirmavam contra o sujeito e sua liberdade individual: falava-se então de estruturalismo "sem sujeito". Penso 
que há na ideologia anti-subjetivista daquela época um erro metodológico. Certamente, as estruturas e as morfologias têm um conteúdo formal (Husserl diria noemático), em parte independente de suas implementações no mundo ou no psiquismo (Husserl diria de suas bases hyléticas e de suas sínteses noéticas). Para estudá-las enquanto entidades abstratas (noemáticas), é legítimo aplicar o princípio metodológico da imanência tão caro a Hjelmslev. Mas isso não significa que essas estruturas sejam sociais e que se possa negar o aspecto "physis", o aspecto "technè" e o aspecto "noèsis" delas. Isso simplesmente significa que elas são ideais, o que é inteiramente outra coisa. Os universais formais e as gramáticas puras são instituições simbólicas cuja socialização deve ser entendida no âmbito de uma filosofia social que depende do individualismo metodológico. Este não é o lugar para aprofundar nesse tema, mas a estrutura certamente não é um argumento em favor da eliminação do sujeito. O princípio da imanência aplica-se às idealidades noemáticas, não implementadas, de mundos virtuais possivelmente reais, por exemplo os actantes "de papel" nas ficções. Mas deve ser superado e articulado com verdadeiros mundos, verdadeiros corpos, verdadeiros psiquismos, verdadeiras instituições sociais.

Dito isto, o fato de que o sentido não se reduza a uma instância social não impede que a semiótica e seu modelo actancial devam fazer interface com as ciências sociais. Este trabalho fundamental foi brilhantemente realizado por Eric Landowski com sua interpretação dos actantes narrativos como agentes sociais, de suas modalidades como modos políticos de interação e dos destinadores como instâncias jurídicas.

\section{Convergências ulteriores}

\section{1. $1985-\ldots$}

A semiótica greimasiana dominou meu trabalho por quinze anos (1970-1985). Durante esse período, as afinidades e alianças da morfodinâmica que eu havia transferido para ela foram recebidas como contribuições exógenas por muitos colegas e provavelmente também pelo próprio Greimas.

A partir de meados dos anos 80, outros campos de pesquisa tornaram-se para mim dominantes. É pertinente mencionar três neste contexto.

(1) Em um extremo, a orientação para as neurociências cognitivas e os sistemas complexos com a redistribuição neste novo quadro científico e neste novo meio institucional dos trabalhos morfodinâmicos anteriores sobre a semio-linguística e a fenomenologia da percepção. Isso abrange uma grande parte do meu trabalho no CREA da Ecole Polytechnique: DEA em Ciências Cognitivas, Instituto de Sistemas Complexos, linguística cognitiva (na Califórnia) com Per Aage Brandt (cf. mais acima), seminário com Jean-Michel Roy e Francisco Varela na École Normale Supérieure sobre Naturalização da fenomenologia. 
(2) A genealogia morfológica do estruturalismo (cf. mais acima).

(3) No outro extremo, a estética plástica e literária como semiotização da percepção com a hipótese de que certos escritores e artistas são proeminentes teóricos destas questões. Isto diz respeito (i) a pesquisas sobre Valéry (por exemplo, suas reflexões sobre as formas e padrões das conchas: ligações com os trabalhos de Jean-Claude Coquet); (ii) a pesquisas sobre a fenomenologia da percepção na obra desse "memorialista do visível" que é para mim Proust (a pequena frase de Vinteuil, os sinos de Martinville: ligações com os trabalhos de Marco Jacquemet e Jacques Fontanille) ; (iii) a novas pesquisas sobre o enraizamento das estruturas discursivas nos esquemas espaço-temporais e a implementação do mítico na figuratividade espacial, as paisagens e os percursos geográficos, por exemplo em Stendhal (estreita ligação com as obras de Jean-Jacques Vincensini sobre os mitos melusinianos e a antropologia do imaginário e Michael Nerlich sobre Stendhal, afinidade com as análises de Denis Bertrand sobre Zola em sua tese de 1982, L'espace et le sens, a propósito de Germinal de Zola); (iv) ou ainda a pesquisas sobre as técnicas de composição em pintura e escultura (Laocoon, Rafael, Mantegna, Piero della Francesca, Poussin: ligações com as obras de Louis Marin, Hubert Damisch, Daniel Arasse, Jean-Claude Bonne, Ivan Darrault, Peer Bundgaard, Herman Parret, Anne Henault e Jean-François Bordron, bem como os centros de Umberto Eco em Bolonha e Omar Calabrese em Siena). Uma parte de tudo isso encontra-se em Morphologie et Esthétique e no número 5 de Cognitive Semiotics : Aesthetic Cognition, que editei em 2009 com Peer Bundgaard. Também poder-se-á consultar o artigo mais recente de Ivan Darrault, De l'allégorie à la scène mythique em L'image peut-elle nier? (2016).

Está óbvio que essas pesquisas têm fortes afinidades com a semiótica do espaço, a semiótica visual e o que Greimas implementou no âmbito da estética com Da Imperfeição (1987), trabalho do qual ele nos falava em seu seminário de 1984-85. As afinidades são grandes, por exemplo em arquitetura e em urbanismo, com as reflexões de Pierre Boudon e Manar Hammad sobre as estruturações mereológicas dos edifícios e das cidades com justaposições, encaixes, fronteiras, limiares, assemblagens, conexões, intricações, ancoragem territorial, aspectualidade espaço-temporal.

Mas durante este período de 1985 até hoje, tive o prazer de ver se desenvolver progressos endógenos da semiótica que, frequentemente, entravam em consonância, e até mesmo em ressonância, com minhas tentativas do passado. Gostaria de concluir com algumas dessas outras convergências. 


\section{Semiótica do sensível}

Do precedentemente exposto, entender-se-á que uma das principais convergências terá sido as numerosas maneiras de reintegrar a fenomenologia do sensível no interior da teoria standard: as dimensões perceptivas, fáticas, somáticas do sentido tornaram-se efetivamente dominantes nos anos 1980-1990.

Após a partida para a aposentadoria de Greimas, Jean-Claude Coquet assumiu em 1985 a direção do Laboratoire Analyse du discours (unidade do CNRS criada para Greimas por Bernard Quemada, o responsável do Trésor de la Langue Française) e o orientou para o discurso e a enunciação. Um pouco como eu havia tentado enriquecer a semiótica estrutural com Thom, ele a enriqueceu com Benveniste, cujos cursos ele frequentou no Collège de France a partir de 1965 e que foi sua segunda referência principal.

Em relação ao debate entre sua semiótica "subjetal" e a semiótica "objetal" de Greimas, minha posição era dupla: (i) para a modelagem das estruturas semio-narrativas elementares regidas pelo princípio de imanência, situava-me inteiramente do lado greimassiano como vimos mais acima; (ii), mas, ao mesmo tempo, como igualmente acabamos de tratar, enriqueci essa modelização com a morfodinâmica do mundo natural e da fenomenologia da percepção, o que convergia em muitos pontos com a semiótica "subjetal". Efetivamente, como ele bem explicou em Physis e Logos, Jean-Claude Coquet queria reabilitar o ser e a realidade da physis ao lado da racionalidade do logos. Segundo ele, enquanto uma experiência vivida, o mundo sensível perceptivo e somático não é uma questão de logos e o que ele chama de fenomenologia da linguagem consiste em acoplar logos e physis. Benveniste aí encontra Husserl, tanto isso é verdade que, como Coquet explica em sua entrevista a Amir Biglari, "o corpo é o nível substancial da instância enunciante".

No debate organizado por Ivan Darrault e publicado nas Actes Sémiotiques em 2011, discutimos esses pontos. A principal diferença entre nós é que, além da physis e do logos, a morfodinâmica também é uma teoria da Natureza como techné, o que permite responder à crítica que, por que matemática, o estruturalismo dinâmico está do lado do logos. Para unificar esses pontos de vista complementares, pareceu-nos pertinente propor um seminário comum. E, assim (cf. dito anteriormente), a partir de 1990, o Séminaire de Sémiotique da EHESS se consagrou aos marcos teóricos da semiótica estrutural.

Essas convergências foram aprofundadas por Ivan Darrault, que era próximo de Jean-Claude Coquet. Com a psico-semiótica, a etho-semiótica, em relação às terapias psicomotoras, a subjetividade e a intersubjetividade constitutivas da discursividade passaram igualmente ao primeiro plano. A narratividade e a discursividade de "papel" se implementavam em psiquismos reais, em corpos carnais, em comportamentos vivos e práticas vividas que interagem com o mundo natural e as instituições sociais. Como já disse, a partir de 1997, meu Séminaire de Sémiotique foi coorganizado com Ivan, JeanJacques Vincensini e Michel Costantini. 
Um ponto comum de todas essas abordagens "subjetais" convergentes é que elas envolviam componentes "exógenos" à semiótica, quer se trate de fenomenologia, de ciências cognitivas, quer de psiquiatria. O que é, penso, particularmente notável do ponto de vista da história das ideias terá sido a sua convergência com a semiótica "viva" do sensível, das percepções, das paixões, das emoções decorrentes de progressos endógenos da teoria standard.

A partir de 1991, começou o grande projeto da Semiótica das paixões (GreimasFontanille), que levava em conta o fato de que, como Denis Bertrand formulou bem, a "sensibilidade faz corpo com a língua". As dimensões da sensibilização do discurso e a necessidade de introduzir o corpo na compreensão da enunciação não foram aí levadas em consideração através de interfaces que acoplam a semiótica com outras disciplinas, mas do interior como um aprofundamento de métodos semióticos comprovados garantidos pelo princípio de imanência.

Constata-se também um retorno do sensível nos trabalhos de Eric Landowski sobre a capacidade de apreender, ler e interpretar as expressões dos agentes na "co-presença sensível" de suas interações. Encontrei uma problemática dessa ordem na minha pesquisa sobre o Laocoon como exemplum doloris e Pathosformel no sentido de Aby Warburg, estudando os debates sobre esta obra-prima que aconteceram na Acadêmia no final de século XVII. O objetivo era entender de que modo, como diziam os acadêmicos da época, "a forma externa das partes", "o movimento dos músculos e das veias", permitia "conhecer as emoções e as paixões da alma", como "os signos que ele [Laocoon] faz ver na face e em todas as partes" "nos [faz] ver o mal que ele sente". Este antigo tema da "expressividade" tornou-se hoje central também nas ciências cognitivas para compreender como os sujeitos têm a capacidade de inferir os sentimentos dos outros a partir de suas expressões.

Em suma, como o confirma o título Sémiotique: le sens, le sensible, le réel do colóquio organizado de 11 a 13 de junho de 2010 na Abbaye de Royaumont por Anne Hénault, as contribuições exógenas à semiótica sobre o real e o sensível, com o tempo, tornaram-se endógenas.

\section{Iconicidade intrínseca das estruturas}

Uma última convergência que gostaria de sublinhar é aquela com o tema da iconicidade, como Jean-François Bordron a trata, em particular em L'iconicité et ses images (2011). Desde muito tempo, compartilhamos uma filosofia transcendental da constituição do sentido a partir de descontinuidades e de articulações intensivas. De acordo com Jean-François, a iconicidade vai muito além dos signos icônicos de Peirce. O "momento icônico" é um momento profundo do processo genético da constituição do sentido, e sua "iconicidade intrínseca" liga inseparavelmente entre eles o ser e o sentido, em particular o ser sensível enquanto organização fenomenal e a semiose. Este "momento icônico" intuitivo, pré-conceitual, proto-semiótico é muito próximo do nível morfológico no qual se articulam as estruturas antes de que as unidades que podem servir de referente 
para símbolos sejam constituídas como tal. Reencontra-se aí o iconismo primário de Eco como "limiar inferior da semiótica" (cf. acima). Bordron acrescenta que se trata de um nível mereológico de "composição" e de "preenchimento" de extensões espaço-temporais por qualidades segundas, nível muito próximo dos esboços perceptivos de Husserl (Abschattungen). Reencontra-se assim, do interior da semiótica, as antigas modelizações morfológicas dos esboços que propus na virada dos anos 1970-1980 e que, enquanto tal, não estavam diretamente relacionadas à semiótica standard.

\section{Conclusão}

Numa entrevista, François Rastier explica que o "paradoxo da semiolinguística" é de ter quebrado a solidariedade entre conteúdo e expressão e mantido "um dualismo tradicional entre inteligível e sensível, profundidade semântica e superfície expressiva". Segundo ele, a semiótica greimasiana não era saussuriana sobre esse ponto porque ela visava uma "semântica universal, transcendente aos vários sistemas de signos" [3]. Tudo o que temos lembrado aqui consistiu em superar esse paradoxo.

Essa foi uma bela aventura. E quando recapitulo retrospectivamente essas memórias e esses percursos do lado de Greimas, fico ainda muito mais impressionado pela estatura intelectual desse mestre do que eu o fui quando de meus primeiros encontros. Em 12 de junho de 1985, Greimas concluiu vários anos de seminários sobre o Verdadeiro, o Belo e o Bom. E acredito que foram bem esses transcendentais que animaram sua obra e que ele nos transmitiu.

Traduzido do francês por Ana Claudia de Oliveira.

Jean Petitot é investigador e professor do Centre d'Analyse et de Mathématique Sociales (CAMS) da École des Hautes Études en Sciences Sociales, Paris (EHESS-PSL). De 2000 a 2006, foi responsável pelo Mestrado de Ciências cognitivas e diretor do Centre de Recherche en Épistémologie Appliquée (CREA) da École Polytechnique. De 2000 a 2009, atuou também como professor do Departamento de Humanidades e Ciências Sociais dessa mesma instituição. Seus trabalhos tratam da epistemologia das matemáticas e da física matemática dos sistemas dinâmicos e da teoria das singularidades, da neurociência cognitiva, dos sistemas complexos e da fenomenologia da percepção. Entre seus livros em relação direta com a semiótica destacam-se Morphogenèse du Sens. Pour un schématisme de la structure e Morphologie et Esthétique.

petitot@ehess.fr 


\section{Referências}

AAVV, Recherches sémiologiques: I'analyse structurale du récit, Communications, 8, 1966.

ANDERSON, J. M. The Grammar of Case. Towards a Localistic Theory. Cambridge: University Press, 1971.

ARRIVE, M.; COQUET, J.-C. (Eds.). Sémiotique en jeu. A partir et autour de l'œuvre d'A. J. Greimas (Colloque de Cerisy, 4-14 août 1983). Paris-Amsterdam: Hadès-Benjamins, 1987.

BENVENISTE, E. Problèmes de linguistique générale. Paris: Gallimard, 1966.

BERTRAND, D. L'espace et le sens: Germinal d'Emile Zola. Thèse, 1982. Paris-Amsterdam: HadèsBenjamins, 1985.

BIGLARI, A. (Ed.). Entretiens sémiotiques. Limoges: Lambert-Lucas, 2014.

BORDRON, J.-F. L'iconicité et ses images. Paris: Presses Universitaires de France, 2011.

BOUDON, P. Les ordres de la figuration. Communications, 34, 1981.

. Le Paradigme de l'architecture. Montréal: Balzac,1992.

BRANDT, P. A. La Charpente modale du sens: pour une sémio-linguistique morphogénétique et dynamique. Thèse d'État, Paris III, 1986. Amsterdam: John Benjamins, 1992.

BRODEN, T. F. (Ed.). Foreword to A. J. Greimas: Life, Work and Theory. Special issue of Semiotica. The Journal of the International Association for Semiotic Studies. Mouton de Gruyter, Vol. 214, 2017.

COQUET, J.-C. (Ed.). Sémiotique. L'école de Paris. Paris: Hachette, 1982.

Physis et Logos: une phénoménologie du langage. Saint Denis: Presses Universitaires de Vincennes, 2007.

COQUET, J.-C.; PETITOT, J. In: DARRAULT, I. (Ed.). Le débat. Actes Sémiotiques, 114, 2011.

COSTANTINI, M.; DARRAULT, I. (Eds.). Sémiotique, Phénoménologie, Discours. Hommage à JeanClaude Coquet. Paris: L'Harmattan, 1996.

COURTES, J. Lévi-Strauss et les contraintes de la pensée mythique. Tours: Mame, 1973.

. Introduction à la sémiotique narrative et discursive. Paris: Hachette, 1976.

DARRAULT, I. De I'allégorie à la scène mythique. In: BADIR, S.; DONDERO, M. G. (Eds.). L'image peut-elle nier? Presses Universitaires de Liège, 2016.

DARRAULT, I.; KLEIN, J.-P. Pour une psychiatrie de l'ellipse: les aventures du sujet en action. Limoges: Pulim, 1993.

DELATTRE, P. From Acoustic Cues to Distinctive Features. Phonetica, 18, 4, 1968.

DELEUZE, G. A quoi reconnaît-on le structuralisme? In: CHATELET, F. (Ed.). Histoire de la philosophie. Paris: Hachette, 1973.

DUCROT, O.; TODOROV, T.; SPERBER, D.; SAFOUAN, M.; WAHL, F. Qu'est-ce que le structuralisme? Paris: Seuil, 1973.

DURAND, G. Le décor mythique de La Chartreuse de Parme. Paris: José Corti, (1961) 1983.

ECO, U. Kant e l'Ornitorinco. Milan: Bompiani, 1997. Trad. fr., Kant et l'Ornithorynque, Paris: Grasset, 1999. 
FILLMORE, C. The Case for case. In: BACH, E.; HARMS, R. T. (Eds.). Universals in Linguistic Theory. New York: Holt, Rinehart \& Winston, 1968.

The Case for case reopened. Syntax and Semantics, 8, 1977.

FONTANILLE, J. Les Espaces subjectifs. Introduction à la sémiotique de l'observateur. Paris: Hachette, 1989.

.Sémiotique du visible: des mondes de lumière. Paris: Presses Universitaires de France, 1995.

GOETHE, J. W. von. Werke. Edition de Hambourg, vol. 1-14. TRUNZ, E. (Ed.). Munich: Deutscher Taschenbuch Verlag. 1982.

La Métamorphose des Plantes (1780-1830) (trad. H. Bideau).Paris: Triades, 1975.

Sur Laocoon (1798). Ecrits sur l'Art. Paris: Klincksieck, 1983.

GREIMAS, A. J. Sémantique structurale. Recherche de méthode. Paris: Larousse, 1966.

Du Sens. Paris: Seuil, 1970.

Maupassant. La sémiotique du texte. Paris: Seuil, 1976.

Du Sens II. Paris: Seuil, 1983.

De I'Imperfection. Périgueux: Fanlac, 1987.

GREIMAS, A. J.; COURTÉS, J. Sémiotique. Dictionnaire raisonné de la théorie du langage. Paris: Hachette, 1979.

GREIMAS, A. J.; FONTANILLE, J. Sémiotique des passions. Paris: Seuil, 1991.

GROUPE 107. Sémiotique de I'Espace. Paris: Denoël-Gonthier, 1979.

HAIMAN, J. (Ed.). Iconicity in Syntax. Amsterdam: Benjamins, 1985.

HAMMAD, M. Lire I'espace. Comprendre l'architecture. Limoges: Presses Universitaires de Limoges, 2006. 2015.

Sémiotiser l'espace. Décrypter architecture et archéologie. Essais sémiotiques. Paris: Geuthner,

HENAULT, A. Histoire de la sémiotique. Paris: Presses Universitaires de France, 1992.

(Ed.). Sémiotique: le sens, le sensible, le réel (colloque, 11-13 juin 2010). Abbaye de Royaumont (à par.).

HJELMSLEV, L. La catégorie des cas (1935). Munich: Wilhelm Fink Verlag, 1972.

Prolégomènes à une théorie du langage. Paris: Minuit, 1968.

— La stratification du langage. Word, 10, 2-3, 1954.

HOLENSTEIN, E. Jakobson ou le structuralisme phénoménologique. Paris: Seghers, 1974.

HUSSERL, E. Logische Untersuchungen (1900-1901). Halle: Max Niemeyer, 1913.

Recherches Logiques. Paris: Presses Universitaires de France, 1969-1974.

. Ideen zu einer reinen Phänomenologie und phänomenologischen Philosophie, I, (1913).

Husserliana 3. (W. Biemel Ed.). La Haye: M. Nijhoff, 1950.

. Idées directrices pour une Phénoménologie. Trad. P. Ricoeur). Paris: Gallimard, 1982.

Erfahrung und Urteil. Untersuchungen zur Genealogie der Logik (1939), (L. Landgrebe éd.).

Hamburg: Claassen \& Goverts, 1948.

- Expérience et Jugement. Recherches en vue d'une généalogie de la logique (trad. D. SoucheDagues). Paris: PUF, 1970. 
. Idées directrices pour une Phénoménologie II: Recherches phénoménologiques pour la Constitution (trad. E. Escoubas). Paris: Presses Universitaires de France, 1982.

JAKOBSON, R.; FANT, G.; HALLE, M. Preliminaries to Speech Analysis. Cambridge: MIT Press, 1952/1967.

KANT, I. Metaphysische Anfangsgründe der Naturwissenschaft (1786). Kants gesammelte Schriften. Band IV. Preussische Akademie der Wissenschaften. Berlin: Georg Reimer, 1911. 1971.

Premiers Principes métaphysiques de la Science de la Nature (trad. J. Gibelin). Paris: Vrin,

Kritik der Urtheilskraft (1790). Kants gesammelte Schriften. Band V. Preussische Akademie der Wissenschaften. Berlin: Georg Reimer, 1913.

Critique de la Faculté de Juger (trad. A. Philonenko). Paris: Vrin, 1979.

LAKOFF, G. Cognitive semantics. Meaning and Mental Representations. In: ECO, U.; SANTAMBROGIO, M.; VIOLI, P. (Eds.). Advances in Semiotics. Bloomington: Indiana University Press, 1988.

LANDOWSKI, E. La société réfléchie. Essais de socio-sémiotique. Paris: Seuil, 1989.

. Passions sans nom. Paris: PUF, 2004.

LANGACKER, R. W. Foundations of Cognitive Grammar. Stanford: Stanford University Press, vol. I, 1987 ; vol. II, 1991.

. «Structural Syntax : The View from Cognitive Grammar . In: PETITOT, J. (Ed.). Linguistique cognitive et Modèles dynamiques. Sémiotiques, 6-7, 1994.

LESSING, G. E. Laocoon (1766). Trad. Courtin (1866). Paris: Hermann, 1990.

LÉVI-STRAUSS, C. Les structures élémentaires de la parenté. Paris: Presses Universitaires de France, 1949.

Anthropologie structurale. Paris: Plon, 1958.

— Le cru et le cuit. Paris: Plon, 1964.

MERLEAU-PONTY, M. Résumés de Cours. Collège de France 1952-1960. Paris: Gallimard, 1968.

. Phénoménologie de la perception. Paris: Gallimard, 1976.

PARRET, H. Au nom de I'hypotypose. In: PETITOT, J.; FABBRI, P. (Eds.). Au Nom du Sens (Colloque de Cerisy sur U. Eco). Paris: Grasset, 2000.

PERRON, P.; COLLINS, F. Paris School of Semiotics. Amsterdam: Benjamins, 1989.

PETITOT, J. Topologie du carré sémiotique. Études littéraires, 1977.

. Saint-Georges: Remarques sur l'espace pictural. In: GROUPE 107 (Ed.). Sémiotique de I'Espace. Paris: Denoël-Gonthier, 1979.

Pour un schématisme de la structure: de quelques implications sémiotiques de la théorie des catastrophes. Thèse d'État, EHESS, 4 vol., 1982.

Les catastrophes de la parole. De Roman Jakobson à René Thom. Paris: Maloine, 1985.

. Morphogenèse du Sens. Pour un schématisme de la structure. Paris: Presses Universitaires de France, 1985. VIII, 35, 1985.

Jugement esthétique et sémiotique du monde naturel chez Kant et Husserl. Actes Sémiotiques. $\overline{\mathrm{XXVIII}}(2-3)$.

Approche morphodynamique de la formule canonique du mythe. L'Homme, 106-107, 
Physique du sens. Paris: Editions du CNRS, 1992.

Morphologie et Esthétique. Paris: Maisonneuve et Larose, 2004.

Cognitive Morphodynamics. Dynamical Morphological Models of Constituency in Perception and Syntax. Berne: Peter Lang, 2011.

Semiotic enargeia: a tribute to Umberto Eco. In: The Philosophy of Umberto Eco. The Library of Living Philosophers. Open Court Publishing Company. La Salle: Illinois, 2016.

PETITOT, J.; VARELA, F.; ROY, J.-M.; PACHOUD, B. (Eds.). Naturalizing Phenomenology: Issues in Contemporary Phenomenology and Cognitive Science. Stanford: University Press, Stanford, 1999.

PETITOT, J.; BUNDGAARD, P. (Eds.). Aesthetic Cognition, in Cognitive Semiotics, 5, 2009.

POTTIER, B. Sémantique générale. Paris: Presses Universitaires de France, 1992.

Représentations mentales et catégorisations linguistiques. Paris-Louvain: Peeters, 2000.

PROPP, V. Morphologie du conte. Trad. C. Ligny. Paris: Gallimard, 1970.

RASTIER, F. Sémantique interprétative. Paris: Presses Universitaires de France, 1987.

. Entretien. In: BIGLARI, A. (Ed.). Entretiens sémiotiques. Limoges: Lambert-Lucas, 2014.

RICOEUR, P. La Grammaire narrative de Greimas. Actes Sémiotiques-Documents, II, 15, 1980.

SCUBLA, L. Lire Lévi-Strauss. Paris: Odile Jacob, 1998.

TESNIERE, L. Eléments de syntaxe structurale. Paris, Klincksieck, 1959.

TALMY, L. Toward a Cognitive Semantics. Vol. I, Concept Structuring Systems. Vol. II: Typology and Process in Concept Structuring. Cambridge: MIT Press, 2000.

THOM, R. Topologie et signification. L'Age de la Science, 4, 1968.

.Topologie et Linguistique. Essays on Topology and Related Topics. Berlin: Springer, 1970.

. Stabilité Structurelle et Morphogenèse. New York-Paris: Benjamin-Édiscience, 1972.

18), 1974 .

Modèles mathématiques de la morphogenèse. Paris: Union Générale d'Éditions (coll.10-

Structures cycliques en sémiologie. Actes Sémiotiques, V, 47-48, 1983.

. Esquisse d'une sémiophysique: Physique aristotélicienne et théorie des catastrophes, Paris, InterÉditions, 1989.

Apologie du logos. Paris: Hachette, 1990.

VINCENSINI, J.-J. Pensée mythique et narration médiévales. Paris: Honoré Champion, 1996.

WILDGEN, W. Catastrophe Theoretic Semantics. An Elaboration and Application of René Thom's Theory. Amsterdam: Benjamins, 1982.

ZILBERBERG, C. Essais sur les modalités tensives. Amsterdam: Benjamins, 1981.

Eléments de grammaire tensive. Limoges: Pulim, 2006. 